\title{
Triagem Neonatal do Hipotireoidismo Congênito: Novas Conquistas... Novos Desafios...
}

\begin{abstract}
TRIAGem NeONATAL É UMA CORRIDa contra o tempo. Assegurar que todas as etapas envolvidas na coleta de sangue, no envio de amostras, na análise de resultados, na convocação de casos supeitos, na confirmação do diagnóstico e no início do tratamento ocorram sem erros e no menor tempo possível exige sincronia e agilidade dos serviços de triagem neonatal. Além disso, demanda também boa parcela de envolvimento da sociedade (1).

Assistimos a uma mudança muito grande na triagem neonatal no Brasil nos últimos anos. Editoriais anteriores dos Arquivos Brasileiros de Endocrinologia e Metabologia (ABE\&M) têm mostrado essas mudanças $(2,3)$. Até o ano de 2001, a triagem neonatal no Brasil era realizada por iniciativa de diferentes instituições, com grandes diferenças entre os vários Estados, apesar de a existência de leis federais desde 1990 que tornavam obrigatória a realização dos testes. A implementação do Programa Nacional de Triagem Neonatal (PNTN), mediante a Portaria do Ministério da Saúde no ${ }^{\circ 22}$, de junho de 2001, tornou viável a implantação da triagem neonatal em todos os Estados. Em virtude de diferentes níveis de organização das redes assistenciais existentes nos Estados e da diversidade das características populacionais existentes no País, o PNTN foi se implantando em fases: fase I - fenilcetonúria e hipotireoidismo congênito (HC); fase II - patologias da fase anterior, anemia falciforme e outras hemoglobinopatias; fase III - patologias da fase anterior e fibrose cística. Atualmente, somente três Estados estão na fase III (MG, PR, SC). Com esse avanço, todos os processos analíticos, ambulatoriais e tratamento são atualmente subsidiados pelo Sistema Único de Saúde (SUS) aos serviços credenciados, ora denominados Serviços de Referência em Triagem Neonatal (SRTN) (4).

O diagnóstico precoce e adequado representa a base filosófica dos programas de triagem neonatal mundiais. Dessa forma, a definição de valores de normalidade adequados para diferenciar indivíduos que necessitam de tratamento ou não, bem como a rapidez dos procedimentos, é fundamental para que se atinjam esses objetivos e para evitar estresse desnecessário às famílias. A divulgação da estratégia adotada pelos SRTNs na pesquisa dessas enfermidades, a prevalência e demais indicadores da triagem neonatal contribui para $\mathrm{o}$ conhecimento, o desenvolvimento e a busca de melhorias locais diante de dificuldades apontadas.

O artigo de Ramalho e col., publicado no presente número dos ABE\&M, mostra a evolução do Programa de Triagem Neonatal para HC em um Estado do Nordeste do Brasil (5). Outros dois trabalhos publicados pelo mesmo grupo nos ABE\&M, em 2000 e 2004, mostram como os desafios estão sendo enfrentados $(6,7)$. Partiu-se de uma cobertura inicial de $15 \%$, chegando em $76,3 \%$ no estudo atual. A idade de coleta das amostras, a avaliação e o tratamento dos casos suspeitos também diminuíram. A preocupação com os resultados falsonegativos é uma constante entre os serviços de triagem neonatal, o que levou os
\end{abstract}

\section{editorial}

\section{SuzANa Nesi França \\ MOUSSELINE TORQUATO DOMINGOS}

Professora adjunta da Unidade de Endocrinologia Pediátrica do Departamento de Pediatria da Universidade Federal do Paraná, médica da Fundação Ecumênica de Proteção ao Excepcional, Curitiba, PR, Brasil (SNF);

Chefe do Laboratório do Centro de Pesquisas da Fundação Ecumênica de Proteção ao Excepcional, coordenadora estadual da Triagem Neonatal, Curitiba, PR, Brasil (MTD). 
autores a utilizarem níveis de corte de TSH de 5,2 $\mu \mathrm{U} /$ $\mathrm{mL}$. O índice de reconvocação observado foi de $0,52 \%$, que é alto em relação à média nacional de $0,25 \%$ (4). $\mathrm{O}$ valor de corte de TSH utilizado foi fundamentado na distribuição dos valores de TSH na população considerada normal (5). Os demais serviços que utilizam a metodologia imunofluorimétrica tendem a utilizar valores de corte próximos à $10 \mu \mathrm{U} / \mathrm{mL}(1,4,8,9)$. Nesse método, deve-se dar especial atenção ao aparecimento de resultados limítrofes (OUT ou 0,01), que quando freqüentes podem indicar problemas na técnica de ensaio ou calibração de equipamentos, gerando falsos resultados. A utilização de controles baixos e altos e padrões internacionais de controle de qualidade são requisitos fundamentais nos processos analíticos utilizados na triagem neonatal $(1,4)$. A ampla variação da idade de coleta da amostra inicial observada no estudo ( 2 a 312 dias) e da amostra para confirmação do diagnóstico dificulta a utilização de um único valor de corte para o TSH e talvez possa induzir a resultados imprecisos, entretanto, seria mais adequado uniformizar a coleta em vez de utilizar valores de corte diferenciados (9).

O número de resultados falso-positivos encontrados $(47,9 \%$ ou 119 crianças) também é alto. Outro grupo que merece atenção especial é o grupo de casos suspeitos de HC ou hipertireotropinemia (99 crianças). Desse grupo, 87 apresentavam valores séricos de TSH abaixo de $10 \mu \mathrm{U} / \mathrm{mL}$, com $\mathrm{T}_{4}$ normal (5). O tratamento deste último grupo ainda é controverso na literatura, e estudos adicionais poderão estabelecer a sua necessidade ou não $(1,9)$.

É importante que cada SRTN conheça suas dificuldades e estabeleça critérios e metas para reduzir o impacto desses problemas sobre a triagem nas diversas fases. Nesse sentido, avaliações e relatos como os do grupo de Ramalho e col. são fundamentais. Só se entende como Programa de Triagem Neonatal quando todas as ações concorrem para a promoção da saúde da criança e o bem-estar da família. A melhora da triagem neonatal no Brasil depende disso, pois temos tecnologia de primeiro mundo disponível, mas esbarramos em falta de infra-estrutura. Deve-se ter como desafios a serem vencidos: atingir $100 \%$ de cobertura, utilização de padrões internacionais de controle de qualidade, diminuir idades de coleta e início do tratamento (principalmente de casos mais graves), orientação contínua e busca ativa. Mostrar evolução a longo prazo dos casos detectados com valores de TSH limítrofes e avaliação cognitiva também é fundamental para que se possa de- finir a melhor estratégia para o rastreamento. A sociedade em geral tem de ser mais envolvida. Para isso, são fundamentais os programas de educação e esclarecimento $(1,4,8-10)$.

A triagem neonatal mudou drasticamente o prognóstico dos pacientes portadores de $\mathrm{HC}$, entretanto, a importância do médico e dos profissionais da saúde não diminuiu. É sua responsabilidade garantir que não haja atrasos na coleta do teste, no diagnóstico e no tratamento do paciente com HC. O tratamento precoce e contínuo garante a qualidade de vida da criança acometida.

\section{REFERÊNCIAS}

1. American Academy of Pediatrics; American Thyroid Association; Lawson Wilkins Pediatric Endocrine Society. Update of newborn screening and therapy for congenital hypothyroidism. Pediatrics. 2006;117(6):2290-303.

2. Nesi-França S, Sandrini R. Editorial: Rastreamento neonatal do hipotireoidismo congênito. Arq Bras Endocrinol Metab. 1997;41(1):III-IV.

3. Meirelles RMR. Editorial: Triagem neonatal: ficção ou realidade? Arq Bras Endocrinol Metab. 2000;44(2):119-20.

4. Carvalho TM, Santos HP, Santos ICGP, Vargas PR, Pedrosa J. Newborn screening: a national public health programme in Brazil. J Inherited Metab Dis. 2007;30(4):615-21.

5. Ramalho ARO, Ramalho RJR, Oliveira CRP, Santos EG, Oliveira MCP, Aguiar-Oliveira MH. Programa de triagem neonatal para hipotireoidismo congênito no nordeste do Brasil: critérios diagnósticos e resultados. Arq Bras Endocrinol Metab. 2008;52(4):617-27.

6. Ramalho RJR, Valido DP, Oliveira MH. Avaliação do Programa de Triagem para o Hipotireoidismo Congênito no Estado de Sergipe. Arq Bras Endocrinol Metab. 2000;44(2):157-61.

7. Ramalho RJR, Ramalho ARO, Oliveira CRP, Aguiar-Oliveira $\mathrm{MH}$. Evolução do Programa de Triagem Neonatal para o Hipotireoidismo Congênito e Fenilcetonúria no Estado de Sergipe de 1995 a 2003. Arq Bras Endocrinol Metab. 2004;48(6):890-6.

8. Nesi-França S, Pereira RM, Lara F, Pelaez JM, Morizaki TMY, Ditzel EC, et al. Triagem Neonatal para Hipotireoidismo Congênito no Estado do Paraná - Avaliação de 601 Casos Detectados em 14 anos. Rev Med Minas Gerais. 2005;15(2):83.

9. Grüters $A$, Krude $H$. Update on the management of congenital hypothyroidism. Horm Res 2007;68(suppl 5):107-11.

10. Kreisner E, Schermann L, Camargo-Neto E, Gross J L. Predictors of intellectual outcome in a cohort of brazilian children with congenital hypothyroidism. Clin Endocrinol. (Oxf) 2004;60:250-5.

\section{Endereço para correspondência}

Suzana Nesi França

Johns Hopkins Hospital, Department of Pediatrics and Medicine, Metabolism Division

600 N. Wolfe Street/CMSC 10-113

Baltimore, MD - EUA 21287

E-mail: snesifranca@hotmail.com 